\title{
La autonomía universitaria
}

\author{
Por ANIBAL ISMODES C.
}

La Reforma Universitaria plantea numerosos temas de orden educacional. económico y jurídico que rebalsan las consideraciones estatales y exigen una organización independiente en sus postulados filosóficos. El problema central no debe encontrarse en los arranques demagógicos, tampoco en las simples transformaciones docentes y menos todavía en su identificación política con las aspiraciones transitorias del momento. La raíz, capaz de obtener el jugo necesario para transformar la Universidad, es, sin duda alguna, la autonomía. Al respecto dos tesis discurren opuestamente: a) la que afirma que las Universidades han sido fundadas y sostenidas por el Estado que rigió siempre la vida de las mismas; y b) la que les concede amplia independencia dentro de la nación. Previamente, nuestra actitud está definida, pero como no es una actitud de prejuicio, hay que presentar los argumentos que la sostienen, rebatiendo así, directamente y no al soslayo, a las pretensiones invasoras del Estado que al anular la autonomía universitaria, llevaria a esa institución a un nivel subalterno y contradictorio con sus fines de alta cultura.

Las Universidades brotaron del anhelo de expresión en formas más altas y distintas, en todos los pueblos de Occidente. Fueron el reflejo selecto de las inquietudes intelectuales de los hombres. Constituyen floraciones de difícil cultivo amagadas hoy por crisis que levantan fúnebres presentimientos. Son tan graves que muchas gentes se preguntan, si la decadencia de su importancia delata una lamentable. pero cierta languidez precursora de un último y definitivo marchitarse. Así, como en todos los tonos melancólicos posibles se levanta un enorme requiem para la cultura europea, también las plañideras de la Universidad empañan sus ojos para no ver caminos heroicos adormecen su voluntad para entregarse a la abulia o en gestos histéricos de vulgar estridencia disfrazan su ignorancia, con la cortina de humo de sus gritos.

Es un lugar común presuponer que en las Universidades se distribuye la cultura superior, denominación obscura y equívoca que nos induce a preguntar. ¿Cuál es la cultura inferior? En fin, como no es nuestro propósito analizar, por ahora, esta definición, la admitiremos con numerosas reservas y suponiendo por superiores los estudios que trascienden, en la calificación oficial, las etapas primaria y secundaria. Su expresión general ha recorrido diversos momentos en la historia de la humanidad. Los clásicos en la educación griega y romana procuraron un ideal de preparación ciudadana e individual. Primitivamente la paideia es el paradiima educativo. Las pequeñas ciudades anhelan para sus ciudadanos una bella conformación personal, el desarrollo de la energía guerrera, y un ardoroso amor por la vida; cuando 
surge la necesidad de una preparación cultural avanzada. los sofistas toman a su cargo este aspecto. Las múltiples corrientes filosóficas disputan acerca de un ideal eterno de vida, conforme al cual se desenvolverá la educación.

En Atenas y Alejandría, aparte de otras ciudades, crecen establecimientos para proporcionar enseñanza científica sobresaliente. Ađriano dirigió su atención a ellos y fundó en Roma el Ateneo; Marco Aurelio contrató en Atenas, maestros con sueldos fijos para cada ramo de la ciencia. Instituyó ocho cátedras de filosofía, dos para cada una de las cuatro secciones principales y varios puestos docentes para profesores de elocuencia. El progreso de las referidas instituciones, justifica en opinión de algunos críticos, la denominación de Universidades. Dilthey afirma que encontramos en ellas la primera condición básica de la Universidad: un número de profesores colocados y pagados que trabajan conjuntamente, cada uno de los cuales representa una especialidad y respecto a los cuales se hallan sus auditores en una relación completamente libre. Creemos, empero, que la denominación es excesiva, pues, aparte de la Filosofía, el Derecho, las enseñanzas retóricas y gramaticales, los problemas científicos no alcanzaron situaciones ventajosas. La Universidad aparece en el siglo XII y XIII, gracias a dos factores sobresalientes: el Papado y los monjes. No ignoramos por lo afirmado, causas laterales del tipo de las comunas o la proclividad a las asociaciones, rasgo indiscutible de la dimensión histórica medioeral. Puede signarse como embrión a las antiguas escuelas imperiales romanas, a las escuelas palatinas y la organización escolar monacal. Casiodoro y Boecio fundaron establecimientos de enseñanza y, en 529, San Benedicto estableció su monasterio en Monte Cassino, núcleo modelador de todos los monasterios que asumieron la enseñanza de los pueblos bárbaros.

La Universidad insurge como una institución típicamente medioeval y es justo para su comprensión encuadrarla en el ambiente. Estamos muy lejos del prejuicio liberal que se complacía en cubrir con un manto de obscuridad los beneficios del medioevo y reconocemos que difícilmente se puede olvidar el fecundo espíritu de agitación intelectual que conmovía a maestros y discípulos, el generoso ascetismo pródigo en maduraciones posteriores y el sacrificio que importaba vencer dificultades de todo género para vivir la existencia más pura del saber. Alumnos que devotamente acompañaban a luminarias de la Filosofía, de la Teología, de la Medicina y recorrían en peregrinación de luz los campos y las ciudades. Del Studium y del Studium. Generale se ingresa a la universitas magistrorum et scholarum hasta el siglo XIV en que la Universitas pasa a ser la Universidad en su significado contemporáneo. Hay una acción paralela entre los intereses de la comuna y los de la Iglesia. De una concesión arrancada al cancelario de alguna catedral para enseñar fuera de ella se avanza a la facultas ubique docendi, previo examen ante el cancelario y por último a las Bulas que liberan de este requisito. El descubrimiento de los escritos de A'ristóteles representa una de las revoluciones culturales de mayor sacudimiento y Alberto Bollstedt y Tomás de Aquino se empeñan positivamente no sólo en aplicar la deducción metódica sino en preparar el camino por el que habrá de discurrir la posterior experimentación racionalista. Es en Francia y en Italia donde nacen los dos tipos de Universidades que conocemos: París y Bolonia. La primera fué una asociación de maestros y escuelas catedralicias regidas consuetudinariamente, en sus primeros tiempos, y en forma estatutaria, después. Al decir de Wulf, llegó a formar una verdadera República con leyes y tribunales. La de Bolonia adviene como asociaciones de alumnos y su preocupación intelectual se orientó a los fines prácticos de la investigación jurídica. 
Su organización fuẻ definitivamente estatutaria. Los estudiantes se agrupaban por nacionalidades y la agrupación. de naciones formaba la Universidad Legista y la Universidad Artista. Cada Nación proclamaba su Rector y ulteriormente éstos fueron elegidos por las Universidades. La estructura administrativa y educacional de las Universidades de Bolonia y Padua, ha sido investigada por el Dr. José Antonio Encinas en un valioso trabajo.

En los siglos XIII, XIV, XV, brotan Universidades en Alemania, Tnglaterra, España, Bohemia, etc. La Universidad de Praga se funda en 1348, por Carlos IV. para evitar las migraciones de estudiantes; la de Viena en 1365; Heidelberg, en 1385; la de Colonia en 1389; Freiburg, en 1460; Basilea en el mismo año; Ingolstadt en 1472; Tubinga en 1477; Wittemberg en 1502; Francfort en 1506. En el siglo XIII se habían fundado los colegios más antiguos de Oxford: el University, el Balliol y el Merton, con sus propios Estatutos cada uno. Dewonguilla de Galloway, en el colegio de Balliol dispuso que los alumnos sancionaran las disposiciones del Estatuto. Walter de Merton, prelado de la época, puede ser considerado padre del sistema tutorial, clásico de las Universidades en Gran Bretaña, pese a las penetraciones del sistema conferencial que asoma en Manchester. En University, el Rector del Colegio es el fellow más antiguo elegido por sus compañeros. Hay que recordar que el fellow medioeval era un compañero, un universitario, no el profesor o investigador contemporáneo. En Cambridge fué y es célebre el Colegio de Cristo, cuyos Estatutos formulados por Lady Margaret en 1503 están ordenados conforme al patrón de Oxford de modo que muchas características subsisten por el afán tradicionalista que distingue a los ingleses.

Bolonia proyecta su organización en Salamanca y el régimen democrático en que se fundamentaba se trasladó con algunas modificaciones. En Salamanca, el gobierno lo tenían los alumnos que designaban a un Rector entre ellos y que debía dirigir la marcha de la institución. El procedimiento era indirecto: las naciones elegían a sus conciliarios: ocho en total y los conciliarios designaban al Rector. Posteriormente aparecieron los definidores, en número de 20 , con lo que disminuyó la importancia de las asambleas de graduados y estudiantes. En el número de los definidores, la mitad representaba a los estudiantes y la otra mitad a los profesores. Por otra parte, el voto de los alumnos era decisivo en là provisión de cátedras. Cuando la organización democrática institucionalista de la Edad Media decayó, nacen las instituciones colegiales con fines de caridad y asistenciales, pero con estructura administrativa absolutista y pronto se erigen en rivales de la Universidad. Pero, los no colegiados o manteístas defienden sus privileg:os y los conservan. El racionalismo de estado que proponía el mundo moderno ya no es compatible con las fuerzas que distraen su prepotencia y las nuevas Universidades, como la de Alcalá, tienen que estar sujetas a un régimén de autoridad indiscutible. E1 tan decantado principio de autoridad, tal como lo entienden los interesados, no es propio de la Edad Media, sino del ràcionalismo estatal. El estudiante cie Salamanca, magníficamente descrito por la pluma feliz de Arciniegas en ese libro que todo universitario debe leer: "El Estudiante de la Mesa Redonda", abandona lós estudios para iniciar el peregrinaje a la tierra indiana, modelando los tipos de la novela picaresca.

En el Perú los Estudios Generales nacen en el claustro de Santo Domingo, por el primer Provincial de esa orden en el Perú, Fray Tomás de Sán Martín, autorizados por Carlos V. Lánguida vida desarrolló en sus primeros intentos de marcha hasta el virreynato de Toledo. En la partida de nacimiento se le otorgaban las mismas franquicias y libertades de que gozaba 
la Universidad de Salamanca. Los ingresos que le proporcionó Toledo le permitieron crear en 1576, tres cátedras de Letras, tres de Filosofía, de Teo. logía, de Leyes, dos de Cánones y dos de Medicina. En la exposición de motivos del Estatuto Universitario de 1928, declarado en vigor de acuerdo con la ley 6041 se lee: "Durante el Coloniaje la dotación de las cátedras de la Universidad de Lima, se pagaba de diversas rentas de la Corona, principalmente del producto de los novenos decimales reservados al Erario en todas las diócesis del Reino".

Menguó mucho el ánimo democrático de Salamanca, emigrante en el Perú, aunque siempre se conservaron algunos rasgos de la Universidad medioeval. En la española el poder supremo universitario residía en la Asamblea de graduados y estudiantes. En Lima, las Asambleas y Claustros eran formados por los doctores de un modo exclusivo. El Rector debía tener ésa jerarquía y ser elegido por ellos. No se conoce el definitorio y en vez de ocho conciliarios hay cuatro: dos doctores y dos estudiantes. La concesión del voto a los estudiantes para la provisión de las cátedras en los concursos, les fué arrebatada por los disturbios que se promovieron. En 1676 por una cédula real desaparecia ese derecho. Siete personas que ocupaban los más altos cargos en el Virreynato: Arzobispo, deán, maestre escuela del cabildo, oidor más antiguo, inquisidor mayor, Rector de la Universidad y decano de cada Facultad, debian asumir ese mandato. La Universidad luchó por reconquistar sus privilegios. En 1684 se obtiene la expedición de una cédula en virtud de la cual las oposiciones se resolvian con el voto de 25 catedráticos doctores y cuatro alumnos de los colegios. En 1687, todos los catedráticos alcanzan voto y participan de él treintinueve alumnos: nueve de los colegios y treinta manteistas.

No fué agitada la vida de la Universidad por grandes problemas culturales $y$ en tratándose de conocimientos superiores, carecieron de audacia. El tomismo ya decaído, imperaba en las enseñanzas, pero sin la visión ágil y renovadora que le podía prestar un contacto más intimo con el método experimental, posibilidad de la que tampoco podemos reprochar desconocer a los maestros coloniales, pues, hasta el siglo pasado en la misma Europa, se había roto el movimiento de unidad que encontraba en Suárez, Bellarmino, etc., los hercderos de una tradición cabal de pensamiento que si fué audaż al asimilar a Aristóteles en el siglo XIII, también se hubiera coordinado con Bacon y Descartes. El formalismo y la suntuosidad supérflua presidieron todos los actos académicos. La gran aspiración, que todavía no ha sido olvidada, en ciertos medios, era la de ser Doctor y festejar tan magna fecha con todos los ceremoniales bastante complicados y que corresponden dar a conocer al cronista. Su indiscutible decadencia era tan rápida como el crecimiento del prestigio de los colegios jesuitas de San Pedro Nolasco, San Ildefonso, etc. Cuando los religiosos de esta orden fueron expulsados de España y de las colonias, aparece la primera reforma universitaria en 1771, formulada por la Junta de Aplicaciones de los bienes de los Jesuitas. Por lo pronto los bienes de la Orden se aplicaron al Convictorio Carolino y con res. pecto al movimiento educacional, recordemos que los finales del siglo XVIII, presintiendo el futuro republicano, se caracterizan por inquieto afán por escudriñar las posibilidades del Perú. Surge, el "Mercurio Peruano" y las investigaciones son más frecuentes. Belaúnde ha recordado la reforma del siglo XVIII : "Esa reforma que pretendió establecer entre nosotros el estudio del derecho natural y el derecho de gentes; que pretendió introducir las nuevas teorias científicas; que pretendió implantar el método de experimentación en las ciencias médicas; que pretendió establecer la institución de la 
biblioteca aula, de la biblioteca servida por profesores, de la biblioteca, cátedra de bibliografía; que pretendió iniciar el estudio del derecho patrio y el estudio de las cosas americanas". Desgraciadamente, entre sus reformas también se consideraba la supresión del voto de los estudiantes en las oposiciones. Luis E. Valcárcel en su libro: "Ruta Cultural del Perú", tan escasamente comentado, afirma: "La personalidad del Perú, trazada ya en los Comentarios del Inca Garcilaso, define sus contornos en el siglo XVIII, cuando la conocen de visu los sabios europeos, los Condamine, y los Jorge Juan y Antonio Ulloa, los Humboldt y los Bompland". Lamentablemente no se llevaron a su cumplimiento todás las perspectivas que anhelaban los reformadores del momento. La tendencia de los Poderes Públicos para menoscabar la soberanía se intensificó y ya no consistió solamente en el derecho privativo del Virrey para nombrar a determinados catedráticos como el de Matemáticas o su intervención para la provisión de la de Prima de Teología o la de Prima de Escritura sino que se fué francamente a la desaparición de la autonomía universitaria con la secuela de la decadencia universitaria. Puede afirmarse de un modo general que en los albores de la Independencia, la vieja casa de estudios no supo comprender su misión y así pudo decir más tarde José Gregorio Paz Soldán que, en los momentos críticos sólo se escuchó un coro de voces sin emoción: "contra nuestra libertad e independencia, contra la soberanía nacional, ia santidad de las leyes patrias, el derecho de la emisión del pensamiento o de la palabra escrita, las regalias del patronato rracional".

Es, de acuerdo con tales antecedentes, que discrepamos respetuosamente de la opinión de $V$. A. Belaúnde, que en un discurso pronunciado en el banquete ofrecidio por la Universidad Mayor de San Marcos a los estudiantes reunidos en el III Congreso de Fstudiantes de 1912, decía: "Los viejos maestros enseñaban ideas grávidas de acción y aquéllas doctrinas, aquéllos principios, aquéllas enseñanzas crecieron superándose a sí mismas y en su incorporación a la vida deberian convertirse más tarde en las lanzas batalladoras de Junín o en las clarinadas triunfales de Ayacucho".

Mariátegui, en sus 7 Ensayos, apunta que la República señala en sus primeros años un descenso veloz de la importancia de la Universidad. Dice, injustamente, que a los vicios originales de la herencia española se añadieron los de la influencia francesa. Olvida la cosntitución democrática española de la Universidad y su tarea cumplida en los años de autonomía; pero señala cómo la influencia francesa a partir de Napoleón, en su afán de racionalizarlo todo derivó a torpes reformas que han privado a nuestros estudiantes de la unidad contemplativa de la cultura. M. V. Villarán en sus "Esturdios sobre Educación Nacional", afirma: "Con toda su admirable intelectualidad, ese pais no ha podido aún modernizar, democratizar y unificar suficientemente su sistema y sus métodos de educación". Los escritores franceses de más nota son los primeros en reconocerlo: Según el mimético orden desapareció la Antigua Facultad de Artes para ser substituída por las exóticas Facultades de Ciencias y Letras sin ningún sentido profesional o cultural. Hoy día que la importancia de la Pedagogía está en aumento, el paso por estas Facultades significa verdadera rémora, pues, no se vinculan ni con la profesión ni con la cultura. Como la Universidad no es simplemente utilitaria sino que aspira a la cultura integral, filosófica, urge hoy día la Facultad que proporcione la integridad ecuménica de la sabiduría y no la estrecha y angosta visión del profesional encastillado y deformado.

El mal que estamos anotando no es exclusivo de San Marcos. También la Universidad de San Antonio Abad, fundada en el Cuzco en 1598, la Uni- 
versidad del Gran Padre San Agustín, en Arequipa, llamada, primero Academia Lauterana $(15 / \mathrm{IV} / 1821)$ y Universidad desde 1827. La Universidad de Trujillo fundada por Simón Bolívar el 10 de Marzo de 1824 padecian igualmente. Reconstituídas en su actividad no maduraban en frutos de ciencia y antes bien servían para que los ambiciosos forjasen la primera escala que luego los conduciría a la diputación o a ostentar el calificativo doctoral.

Históricamente, la Universidad, en el Perú y en todas partes, vincula la autonomía a su progreso y podemos caracterizar la evolución reformista de la Universidad como una progresiva marcha hacia la autonomía. El Reglamento para San Marcos expedido por Castilla y su Ministro Juan Oviedo, el 28 de Agosto de 1861 y elaborado por una comisión compuesta de Juan Gualberto Valdivia, Miguel de los Ríos, Luis Monzante y Manuel Santos Pasapera, todavía permanece bajo la influencia tutorial del Estado. Cuando se promulgó este Reglamento, así como para el de Instrucción Pública del 1855, la Universidad reclamó. Indudablemente ese gesto provenía de la tendencia de los Colegios a conservar su fisonomía y por eso cuando la dictadura Prado de 1866 decreta que el Convictorio de San Carlos se destine a la enseñanza de las Facultades de Derecho, Ciencias y Letras creándose los Decanos y suprimiendo los internados que al decir de José Simeón Tejeda era "poco conciliable con las aspiraciones, vocación y exigencias sociales del alumnado", los Colegios incorporados a San Marcos protestan. Lo mismo hace el Seminario de Santo Toribio y el Colegio de San Fernando, hoy Facultad de Teología y Medicina respectivamente. Desde esa época queda constituído el sistema de Facultades a imitación del sistema francés napoleónico.

Durante el gobierno de Balta la tendencia centralista del Estado avanza. Pero en 1876, Don Manuel Pardo dicta un Reglamento donde la tutela del Estado se manifiesta menos fuerte. La enseñanza pública deja de đepender de un Ministro cuya solvencia cultural no siempre es evidente. Piérola, por la situación apresurada con que trataba de gobernar, muchas veces hizo tabla rasa de la autonomía conseguida; pero ya estaba en marcha el proceso y $n_{i}$ siquiera la ley de 1928 , forma elegante de escamotearla pudo impedir que se apagasen los propósitos de autonomia. La Universidad necesita su independencia y su libertad frente al Estado; en realidad es un poder tan respetable como los otros porque debe representar a la cultura.

No podemos olvidar otra razón importante que solventa la autonomía en el terreno filosófico-social y es la constitución personal de la Universidad. Persona es un organismo unitario consciente de sus fines y que cumple en sí mismo un valor. No podemos encontrar oposición entre su orientación teleológica y su esencia valorativa. Ambas se complementan. Por otra parte es un organismo y orgánico quiere decir vital. Pero no en el sentido que pretenda derivar la vida exclusivamente de lo corporal o físico. Interpretación materialista, trascendida hoy. Es vital en el sentido aristotélico de un espíritu o ánima, el élan de Bergson, ese agente superior que configura la materia y la presenta viva. Así es como puede afirmarse que el todo es superior a las partes, porque antes de la suma de elementos se presenta el factor que ordena la suma. Pues bien. el espíritu no se dá sólo en el hombre. Se presenta también en las inștituciones. Es lo que las hace organismos. La Universidad presenta la expresión del espíritu que la nima y ordena. Si el hombre vive para cumplir diversos fines: propios y ajenos, también la Universidad presenta fines propios y ajenos. Desde este punto de vista nadie puede discutir el carácter personalista de la Universidad. 
Ahora bien, planteada la estructura personal y admitida, lógicamente entrariamos en contradicción si obstaculizáramos el desenvolvimiento de su carácter esencial, esto es, del caráctér autonómico de la Universidad. Necesariamente dejaría de ser una persona que tiene, kantianamente, un fin en sí misma. La autonomía, es el aire mismo que condiciona la respiración de esa persona moral que es la Universidad. En Filosofía, caben, como hemos demostrado, todas las personas que trasciendan lo corporal y a esas tales se les llama personas morales. Pero su textura esencial es invariable y nada puede modificarla salvo que quieran atentar contra su existencia. La autonomía es lo que la libertad para el hombre, la condición para desenvolverse por sí mismo sin temor a coactivas presencias que embarazan la dinámica libre del espíritu.

No puede desconocerse un hecho social de enorme importancia y que justifica jurídicamente la autonomía. Es la organización estrictamente social de la Universidad. Esta tesis derivada del pluralismo institucionalista de Otto vọn Giercke, puede quedar expresada así: Frente al Estado, creación social que ostenta el poder material, es preciso, en defensa del individuo, le rantar instituciones que amenguen el choque entre individuo y Estado. Desde que Aristóteles formulara el principio de la sociabilidad natural del hombre, nádie ha podido contrastar ese fenómeno evidente y su consecuencia, que es el mismo hombre creando sociedades que perfeccionen su intimidad. Pero, esto implica una distinción: Sociedad no es lo mismo que Estado. El hombre es naturalmente social; pero transitoriamente pertenece a un Estado - hecho histórico relativo que tiene su génesis en la voluntad humana y que puede desaparecer. Es una sociedad entre muchas. Todas ayudan a cumplir el fin último del hombre. Debe tener autonomía o independencia que lo lleve a lograr sus fines. En mucho tiempo, la sociedad estatal bregó con la sociedad eclesiástica, con el Pontificado y logró la victoria porque poseía la fuerza material. En algunos países ha quebrado la sociedad comunal y en Rusia la sociedad de la Cu1tura, esto es, la Universidad. Pinkevich, profesor de la segunda Universidad de Moscú, escribe: "En los tiempos anteriores a la revolución, uno de los problemas más agudos era el de la autonomía a la Universidad. El poder soviético, aun permitiendo. una amplia participación de profesores e instructores en la región universitaria, no reconoce, sin embargo, ningún principio general de autonomía. Por el contrario, sostiene que no puede haber un Estado dentro del Estado, que la Universiclad debe servir los intereses de los que trabajan y no constituir una unidad aislada entre las instituciones del Estado Soviético. " La' nueva educación en la Rusia Soviética”, pág. 360). Es la marcha absorbente del poder estatal llevada a sus últimas consecuencias, de acuerdo con la caracterización del progreso del poder, descrito por Bartolomé Herrera. Empero ética ni jurídicamente se puede sostener esta invasión. El hombre y la Sociedad quieren defenderse contra una criatura que devora a sus progenitores. La mejor defensa se encuentra en la autonomía de sus instituciones.

Histórica, filosófica y jurídicamente queda probada, pues, la necesidad de otorgar y robustecer la autonomía universitaria. El Estado tiene que comprender su carácter social y la eterna permanencia de la Sociedad frente al hecho eventual de la creación del Estado y respetar la autonomía de las instituciones que cree la Sociedad. Por eso afirmo que no está capacitado el Estado para recortar a las Universidades, ni para servirse de ellas en provecho.de sus fines, violentando los fines específicos de la Universidad. Si mueren éstas, es porque la Sociedad lo consiente pero queda advertido que es la muerte también de su expresión cultural. 